\title{
Mechanism of Hypoxic K Loss in Rabbit Ventricle
}

Kalyanam Shivkumar, Nicholas A. Deutsch, Scott T. Lamp, Kien Khuu, Joshua I. Goldhaber, and James N. Weiss

Departments of Medicine (Cardiology) and Physiology, and the Cardiovascular Research Laboratory, UCLA School of Medicine, Los Angeles, California 90095

\begin{abstract}
Although a critical factor causing lethal ischemic ventricular arrhythmias, net cellular $\mathrm{K}$ loss during myocardial ischemia and hypoxia is poorly understood. We investigated whether selective activation of ATP-sensitive $K\left(K_{\text {ATP }}\right)$ channels causes net cellular $K$ loss by examining the effects of the $K_{\mathrm{ATP}}$ channel agonist cromakalim on unidirectional $K$ efflux, total tissue $K$ content, and action potential duration (APD) in isolated arterially perfused rabbit interventricular septa. Despite increasing unidirectional $\mathrm{K}$ efflux and shortening APD to a comparable degree as hypoxia, cromakalim failed to induce net tissue $\mathrm{K}$ loss, ruling out activation of $K_{\text {ATP }}$ channels as the primary cause of hypoxic $K$ loss. Next, we evaluated a novel hypothesis about the mechanism of hypoxic $\mathrm{K}$ loss, namely that net $\mathrm{K}$ loss is a passive reflection of intracellular $\mathrm{Na}$ gain during hypoxia or ischemia. When the major pathways promoting $\mathrm{Na}$ influx were inhibited, net $\mathrm{K}$ loss during hypoxia was almost completely eliminated. These findings show that altered $\mathrm{Na}$ fluxes are the primary cause of net $\mathrm{K}$ loss during hypoxia, and presumably also in ischemia. Given its previously defined role during hypoxia and ischemia in promoting intracellular $\mathrm{Ca}$ overload and reperfusion injury, this newly defined role of intracellular $\mathrm{Na}$ accumulation as a primary cause of cellular $\mathrm{K}$ loss identifies it as a central pathogenetic factor in these settings. (J. Clin. Invest. 1997. 100:1782-1788.) Key words: arrhythmias - myocardial ischemia $\cdot$ potassium channels • sulfonylurea compounds $\bullet$ potassium radioisotopes
\end{abstract}

\section{Introduction}

Net cellular K loss is one of the earliest consequences of myocardial hypoxia and ischemia, beginning within 15-30 s (1). During ischemia, the accumulation of $\mathrm{K}$ in the extracellular space due to the lack of washout by vascular flow has profound electrophysiological effects (2). Membrane depolarization leads to slowing of conduction and altered refractoriness which, in concert with other factors, triggers reentrant ventricular arrhythmias causing sudden cardiac death. Despite considerable study, however, the mechanism of net cellular K loss

Address correspondence to James N. Weiss, Division of Cardiology, Rm 3641 MRL Building, UCLA School of Medicine, Los Angeles, CA 90095. Phone: 310-825-9029; FAX: 310-206-5777; E-mail: jweiss@ ephys.ucla.edu

Received for publication 18 March 1997 and accepted in revised form 1 August 1997.

J. Clin. Invest.

(C) The American Society for Clinical Investigation, Inc. 0021-9738/97/10/1782/07 \$2.00

Volume 100, Number 7, October 1997, 1782-1788

http://www.jci.org during hypoxia and ischemia is still poorly understood. Net $\mathrm{K}$ loss could be caused by increased $\mathrm{K}$ efflux, decreased $\mathrm{K}$ influx, or both. The former explanation has been favored based on the experimental finding that unidirectional $\mathrm{K}$ efflux increases rapidly during myocardial hypoxia $(3,4)$. In addition the bulk cytosolic ATP level does not fall rapidly enough during ischemia to expect significant inhibition of $\mathrm{K}$ influx through $\mathrm{Na}-\mathrm{K}$ pumps $(5,6)$, unless local ATP depletion is more severe in their immediate vicinity. The increase in unidirectional $\mathrm{K}$ efflux during hypoxia and ischemia has been attributed to ATPsensitive $\mathrm{K}$ channels $\left(\mathrm{K}_{\mathrm{ATP}}\right)$, activated by the rapid decrease in the cytosolic ATP/ADP ratio, and other factors (6, 7). However, whether activation of these channels translates into net $\mathrm{K}$ loss has been questioned on theoretical grounds (1). Activation of a membrane $\mathrm{K}$ conductance shortens the action potential duration (APD), ${ }^{1}$ and drives the membrane potential $\left(\mathrm{E}_{\mathrm{m}}\right)$ toward potassium equilibrium potential $\left(\mathrm{E}_{\mathrm{K}}\right)$, so that the decrease in the driving force $\left(\mathrm{E}_{\mathrm{m}}-\mathrm{E}_{\mathrm{K}}\right)$ offsets the increase in membrane $\mathrm{K}$ conductance to minimize net $\mathrm{K}$ loss. This interpretation has been supported by computer simulations (8), but has not been directly tested experimentally. In the first part of this study, we provide the first direct experimental validation by showing that selective activation of $\mathrm{K}_{\mathrm{ATP}}$ channels in the arterially perfused rabbit ventricle does not cause net cellular $\mathrm{K}$ loss, despite increasing unidirectional $\mathrm{K}$ efflux and shortening APD to a comparable degree as hypoxia. In the second part, we present evidence for a novel hypothesis about the mechanism of hypoxic and ischemic $\mathrm{K}$ loss, namely that net $\mathrm{K}$ loss is a passive reflection of intracellular $\mathrm{Na}$ gain during hypoxia or ischemia (1). Specifically, we find that when the major pathways promoting $\mathrm{Na}$ influx during hypoxia are blocked, net $\mathrm{K}$ loss is virtually eliminated.

\section{Methods}

Preparation and solutions. The experimental model was the isolated, arterially perfused rabbit interventricular septum, as described previously (9). Briefly, male New Zealand White rabbits (2-3 kg) were heparinized and anesthetized with an overdose of pentobarbital. The heart was removed via a thoracotomy incision, the septal branch of the left coronary artery was cannulated, and a well-perfused portion of the interventricular septum was isolated by dissection and mounted in a humidified nitrogen-filled chamber maintained at $37^{\circ} \mathrm{C}$. Blowing humidified nitrogen over the surface of the preparation assured that the superficial layer of myocytes also became hypoxic during perfusion with hypoxic solution. A polythene tube (PE-90) anchored at the base was used to collect venous effluent. A ligature placed at the apex of the septum was connected to a tension transducer. Intracellular potential was measured with floating glass microelectrodes filled with $3 \mathrm{M} \mathrm{KCl}$, or monophasic action potentials were recorded using $\mathrm{Ag}-\mathrm{AgCl}$ wire electrode placed on the surface of the

1. Abbreviations used in this paper: APD, action potential duration; CK, cromakalim; EIPA, ethyl-isopropylamiloride; $\mathrm{K}_{\mathrm{ATP}}$, ATP-sensitive K channels. 
heart. The septum was perfused at $37^{\circ} \mathrm{C}$ at a constant flow rate of 1.75 $\mathrm{ml} / \mathrm{min}$ with a modified Krebs solution consisting of (in $\mathrm{mM}$ ): $\mathrm{NaCl}$ $120, \mathrm{KCl} 4, \mathrm{CaCl}_{2} 1.5, \mathrm{NaHCO}_{3} 25, \mathrm{NaH}_{2} \mathrm{PO}_{4} 0.44, \mathrm{MgCl}_{2} 1$, dextrose 5.6 , and insulin $10 \mathrm{U} / \mathrm{ml}$, gassed with $5 \% \mathrm{CO}_{2}-95 \% \mathrm{O}_{2}$ to maintain a $\mathrm{pH}$ of 7.4. The heart was stimulated at 75 beats/min using a bipolar platinum electrode embedded in a corner of the septum. Hypoxia was created by gassing glucose-free perfusate with $5 \% \mathrm{CO}_{2}-95 \% \mathrm{~N}_{2}$. Preparations were allowed to equilibrate at least $1 \mathrm{~h}$ before any experimental intervention.

Radioisotope methods. For ${ }^{42} \mathrm{~K}$ uptake experiments, preparations were perfused with standard perfusate containing 1 or $2 \mu \mathrm{Ci} / \mathrm{ml}$ of ${ }^{42} \mathrm{~K}$. Tissue ${ }^{42} \mathrm{~K}$ radioactivity was measured using a gamma-detecting sodium iodide crystal placed within $2 \mathrm{~cm}$ of the septum, as described previously (9). The radioactivity of the preparation was allowed to approach asymptote (150-180 min) before any experimental intervention. All solutions in a given experiment had identical ${ }^{42} \mathrm{~K}$ activity. Measured cpm were corrected for background and decay. Tissue $\mathrm{K}$ content was expressed as the ratio of corrected cpm to the asymptotic value of corrected cpm reached during control aerobic perfusion.

To measure unidirectional $\mathrm{K}$ efflux rate, septa were loaded with perfusate containing ${ }^{42} \mathrm{~K}(2 \mu \mathrm{Ci} / \mathrm{ml})$ for $>45 \mathrm{~min}$ and then washed out with nonradioactive perfusate. Venous effluent was collected at 1-min intervals and analyzed for radioactivity using a gamma counter (Gamma 5500; Beckman Instruments, Inc., Fullerton, CA). Counts per minute were corrected for background decay, and the rate of unidirectional ${ }^{42} \mathrm{~K}$ efflux was calculated as described previously (9). The control rate of unidirectional $\mathrm{K}$ efflux was established during the initial $15 \mathrm{~min}$ of washout before any experimental intervention.

Drugs and chemicals. All chemicals were obtained from Sigma Chemical Co. (St. Louis, MO), except for ethyl-isopropylamiloride (EIPA), which was obtained from Research Biochemical International (Natick, MA). ${ }^{42} \mathrm{~K}$ was obtained from either New England Nuclear (Boston, MA) or the University of Missouri Research Reactor (Columbia, MO).

Data analysis. All results are summarized as mean \pm SEM. Statistical significance was evaluated by using a Student's $t$ test with a Bonferroni correction for multiple comparisons. $P<0.05$ was considered significant.

\section{Results}

Effects of cromakalim versus hypoxia on cellular $K$ balance. To investigate the role of $\mathrm{K}_{\mathrm{ATP}}$ channels in causing cellular $\mathrm{K}$ loss during hypoxia and ischemia, we examined the effects of selectively activating $\mathrm{K}_{\mathrm{ATP}}$ channels using the drug cromakalim $(\mathrm{CK}, 12 \mu \mathrm{M})$ on APD and either unidirectional $\mathrm{K}^{+}$efflux rate (measured by ${ }^{42} \mathrm{~K}$ washout in six preparations) or total tissue $\mathrm{K}$ content (measured by ${ }^{42} \mathrm{~K}$ uptake in six preparations) in normoxic arterially perfused rabbit interventricular septa paced at 75 beats per minute. The results were compared to substratefree hypoxia in a separate group of five septa (Figs. 1 and 2). Cromakalim shortened APD to a greater extent than substrate-free hypoxia (from $225 \pm 5$ to $70 \pm 7 \mathrm{~ms}$ after cromakalim vs. $202 \pm 9$ to $111 \pm 10 \mathrm{~ms}$ after $30 \mathrm{~min}$ of hypoxia). Cromakalim also increased unidirectional $\mathrm{K}$ efflux rate, peaking at $48 \pm 5 \%$ (from $1.26 \pm 0.13$ to $1.84 \pm 0.24 \mu \mathrm{mol} /$ gram per min, $P<0.05$ ), compared to a $75 \pm 4 \%$ peak increase (from $1.05 \pm 0.06$ to $1.85 \pm 0.19 \mu \mathrm{mol} / \mathrm{gram}$ per min, $P<0.05)$ during substrate-free hypoxia (Fig. 1). The increase in unidirectional $\mathrm{K}^{+}$efflux rate during hypoxia was transient, and by $30 \mathrm{~min}$ returned to the control rate $(1.04 \pm 0.28 \mu \mathrm{mol} / \mathrm{gram}$ per min vs. $1.05 \pm 0.06$ $\mu \mathrm{mol} / \mathrm{gram}$ per min, during control aerobic perfusion). During cromakalim treatment, the increase in unidirectional $\mathrm{K}^{+}$efflux was sustained throughout infusion of the drug.

Accompanying these changes in unidirectional $\mathrm{K}$ efflux
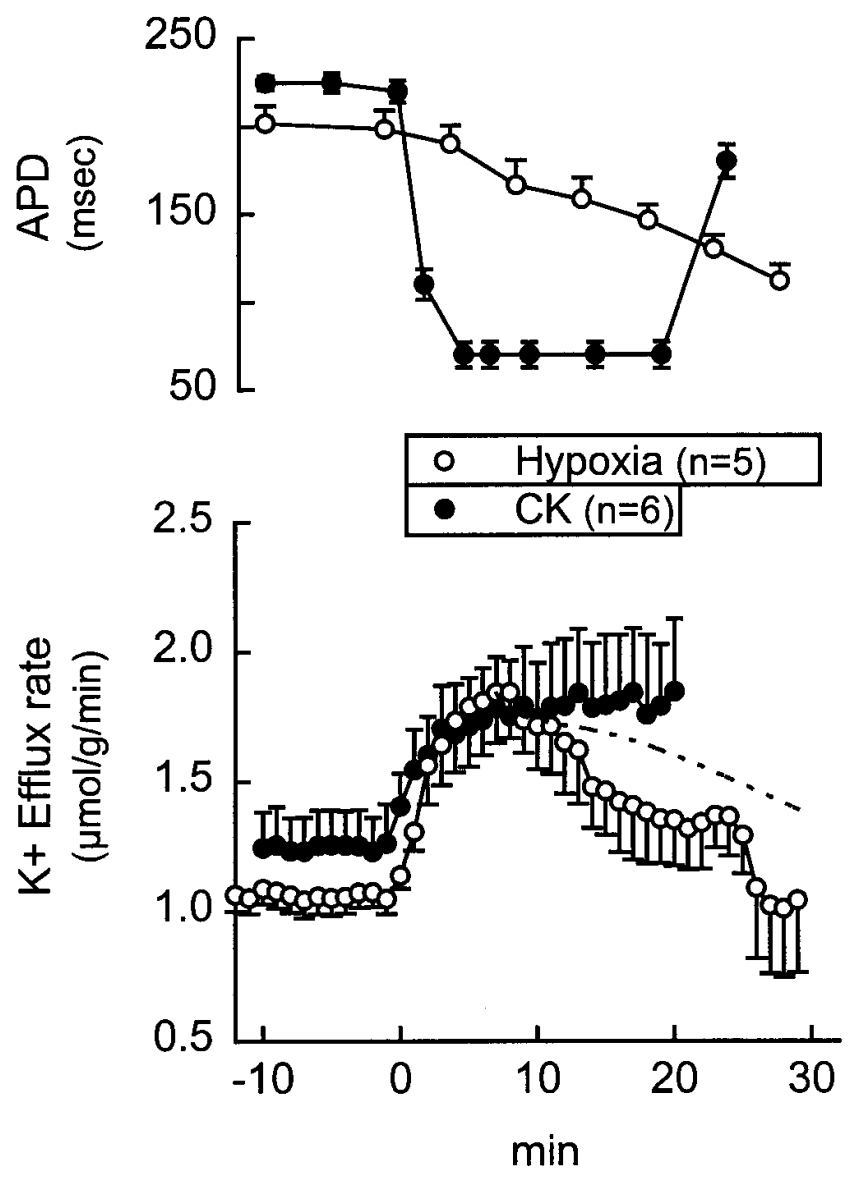

Figure 1. Effects of cromakalim $(C K)$ vs. substrate-free hypoxia on unidirectional $\mathrm{K}$ efflux rate and action potential duration at $90 \%$ repolarization $(A P D)$ in isolated rabbit interventricular septa. Exposure to either $12 \mu \mathrm{M}$ cromakalim for $20 \mathrm{~min}(\mathbf{)})$ or substrate-free hypoxia for 30 min $(\bigcirc)$ caused marked APD shortening (top) and increased unidirectional $\mathrm{K}$ efflux rates (bottom). The increase in unidirectional $\mathrm{K}$ efflux during hypoxia was transient, consistent with the progressive decrease in tissue $\mathrm{K}$ content shown in Fig. 2. The dashed line estimates unidirectional $\mathrm{K}$ efflux corrected for the progressive decrease in intracellular K. Values are mean \pm 1 SEM. Temperature $37^{\circ} \mathrm{C}$, heart rate 75 beats per minute (bpm).

rate, hypoxia led to a $31 \%$ decrease in total tissue $\mathrm{K}^{+}$content over 30 min (Fig. 2). The progressive decrease in intracellular $\mathrm{K}^{+}$content could explain in part the decrease in unidirectional $\mathrm{K}^{+}$efflux after its initial peak during hypoxia (Fig. 1). In the cromakalim-treated hearts, there was no change in total tissue $\mathrm{K}$ content (Fig. 2), despite the comparable increase in unidirectional $\mathrm{K}$ efflux and APD shortening as during hypoxia (Fig. 1). Thus, unlike hypoxia, cromakalim caused unidirectional $\mathrm{K}$ influx to increase comparably to unidirectional $\mathrm{K}$ efflux, so that there was no net $\mathrm{K}$ loss. The cause may be largely attributed to an increase in unidirectional $\mathrm{K}$ influx through $\mathrm{K}_{\mathrm{ATP}}$ and other K channels, as predicted by the Goldman-Hodgkin-Katz equation, rather than an increase in $\mathrm{K}$ influx by the $\mathrm{Na}-\mathrm{K}$ pump or other $\mathrm{K}$ transporters. These results provide the first direct experimental evidence demonstrating that selective activation of $\mathrm{K}_{\mathrm{ATP}}$ does not cause net cellular $\mathrm{K}$ loss, and therefore cannot be the primary cause of net $\mathrm{K}$ loss during hypoxia or ischemia. 

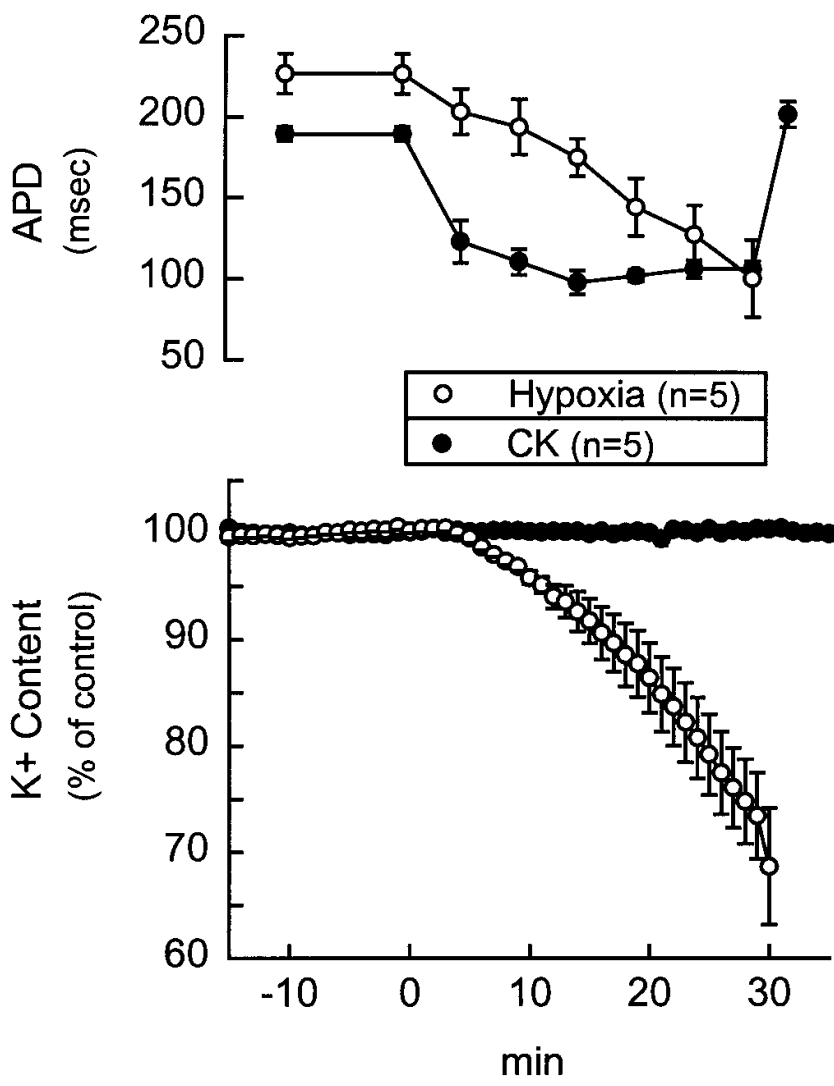

Figure 2. Effects of cromakalim $(C K)$ versus substrate-free hypoxia on action potential duration at $90 \%$ repolarization $(A P D)$ and tissue ${ }^{42} \mathrm{~K}$ content in isolated rabbit ventricular septa. Exposure of the heart to either $12 \mu \mathrm{M}$ cromakalim $(\bullet)$ or substrate-free hypoxia $(\bigcirc)$ for 30 min caused marked APD shortening (top). Substrate free hypoxia caused a progressive decrease in tissue $\mathrm{K}$ content, while $12 \mu \mathrm{M}$ cromakalim did not (bottom). Values are mean \pm 1 SEM. Temperature $37^{\circ} \mathrm{C}$, heart rate $75 \mathrm{bpm}$.

Effect of inhibiting Na influx pathways on tissue $K$ content during hypoxia. Since a selective increase in membrane $\mathrm{K}$ conductance by activation of $\mathrm{K}_{\mathrm{ATP}}$ channels or (by analogy) other $\mathrm{K}$ channels, does not result in net $\mathrm{K}$ loss, and since other postulated mechanisms of hypoxic $\mathrm{K}$ loss, such as anion-coupled $\mathrm{K}$ loss, are also unlikely (10), we considered an alternative hypothesis recently suggested by Wilde and Aksnes (1): namely, that changes in intracellular $\mathrm{Na}$ fluxes, rather than $\mathrm{K}$ fluxes, drive net cellular $\mathrm{K}$ loss during hypoxia and ischemia. We reasoned as follows: it is known that intracellular $\mathrm{Na}$ accumulates during hypoxia at approximately the same or greater rate as extracellular $\mathrm{K}(\sim 0.5 \mathrm{mM} / \mathrm{min})(5)$. For preservation of both electroneutrality and osmotic balance (see Discussion), it is also likely that the sum of intracellular $[\mathrm{Na}]+[\mathrm{K}]$ remains roughly constant, so that any net intracellular $\mathrm{Na}$ gain will reflect a commensurate loss of intracellular $\mathrm{K}$. If this is true, then preventing intracellular $\mathrm{Na}$ accumulation should also prevent cellular K loss. To test this hypothesis, we studied the effects of inhibiting $\mathrm{Na}$ influx pathways on tissue $\mathrm{K}$ loss during hypoxia. Since previous studies have shown that $>90 \%$ of $\mathrm{Na}$ influx is excitation dependent (11), we first examined the effect of quiescence on tissue K content (Fig. 3). Pacing was stopped $10 \mathrm{~min}$ before the onset of hypoxia, and resulted in a slight increase in tissue K content averaging $1 \%(n=4)$. During a subsequent 30 -min period of substrate-free hypoxia, tissue $\mathrm{K}$ content decreased by $3.6 \pm 0.6 \%$, compared to a control group of three continuously paced preparations in which tissue $\mathrm{K}$ content decreased by $18 \pm 3 \%$ over the duration of hypoxia. To inhibit $\mathrm{Na}$ influx pathways more completely, another group of five hearts were exposed to tetrodotoxin $(20 \mu \mathrm{M})$, verapamil $(10 \mu \mathrm{M})$, furosemide $(1 \mathrm{mM})$ and EIPA $(5 \mu \mathrm{M})$, to block $\mathrm{Na}$ channels, L-type $\mathrm{Ca}$ channels, Na-K-2Cl cotransport and $\mathrm{Na}-\mathrm{H}$ exchange, respectively. Exposure to this drug combination, which made the hearts inexcitable, caused a modest $1 \%$ increase in tissue $\mathrm{K}$ content during aerobic perfusion, and nearly completely prevented any decrease in tissue $\mathrm{K}$ content during a subsequent 30-min exposure to substrate-free hypoxia, with tissue $\mathrm{K}$ content falling by only $0.8 \pm 0.8 \%(P<$ 0.05 compared to quiescent hearts) (Fig. 3). These findings strongly support the hypothesis that tissue $\mathrm{K}$ loss during hypoxia is driven primarily by alterations in $\mathrm{Na}$ fluxes, resulting from either increased $\mathrm{Na}$ influx, decreased $\mathrm{Na}$ efflux via the Na-K pump, or both.

Effects of promoting or inhibiting activation of $K_{A T P}$ channels during hypoxia on tissue $K$ loss. Although our findings exclude activation of $\mathrm{K}_{\mathrm{ATP}}$ channels as the primary cause of net cellular $\mathrm{K}$ loss during hypoxia or ischemia, it remains possible that alterations in membrane $\mathrm{K}$ conductance may modulate net $\mathrm{K}$ loss in these settings, for example by secondarily affecting $\mathrm{Na}$ fluxes and intracellular $\mathrm{Na}$ accumulation. To test this possibility, we examined the effects on tissue $\mathrm{K}$ content of either pharmacologically promoting or inhibiting activation of $\mathrm{K}_{\mathrm{ATP}}$ channels during substrate-free hypoxia in rabbit septa paced at 75 beats per minute. Fig. 4 shows the effects of preexposing five septa to $5 \mu \mathrm{M}$ cromakalim before a 30-min episode of hypoxia. The dose of cromakalim was chosen to cause only mild APD shortening during aerobic perfusion (from $223 \pm 13$ to $187 \pm 12 \mathrm{~ms}$ ), yet to significantly accelerate the rate of initial APD shortening during hypoxia. Despite the accelerated activation of $\mathrm{K}_{\mathrm{ATP}}$ channels during hypoxia, net tissue $\mathrm{K}$ content decreased to a similar extent throughout the $30 \mathrm{~min}$ of hypoxia in the presence or absence of cromakalim.

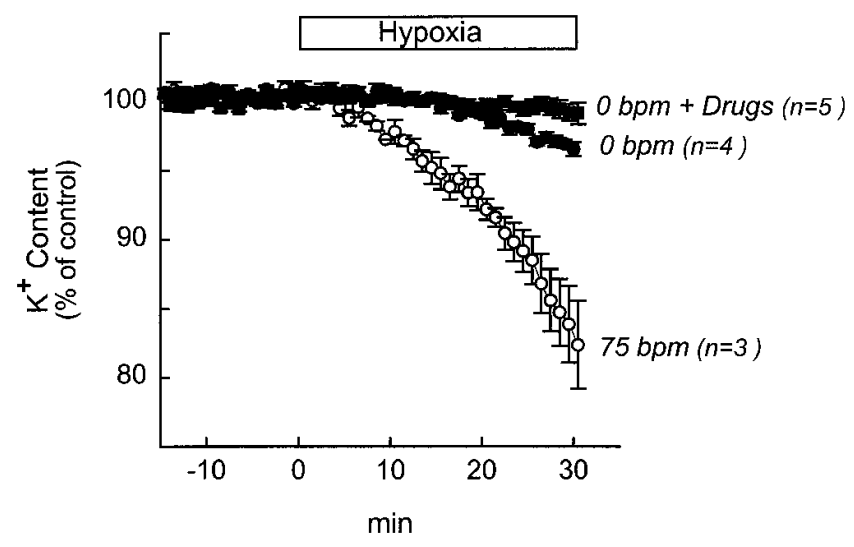

Figure 3. Effects of $30 \mathrm{~min}$ of substrate-free hypoxia on tissue ${ }^{42} \mathrm{~K}$ content in septa paced at $75 \mathrm{bpm}(\bigcirc, n=3)$, unpaced septa $(\bullet, n=$ 4), and unpaced septa pretreated for $10 \mathrm{~min}$ with tetrodotoxin, EIPA, furosemide, and verapamil $(\boldsymbol{\square}, n=5)$. Values are mean \pm 1 SEM. Temperature $37^{\circ} \mathrm{C}$. 


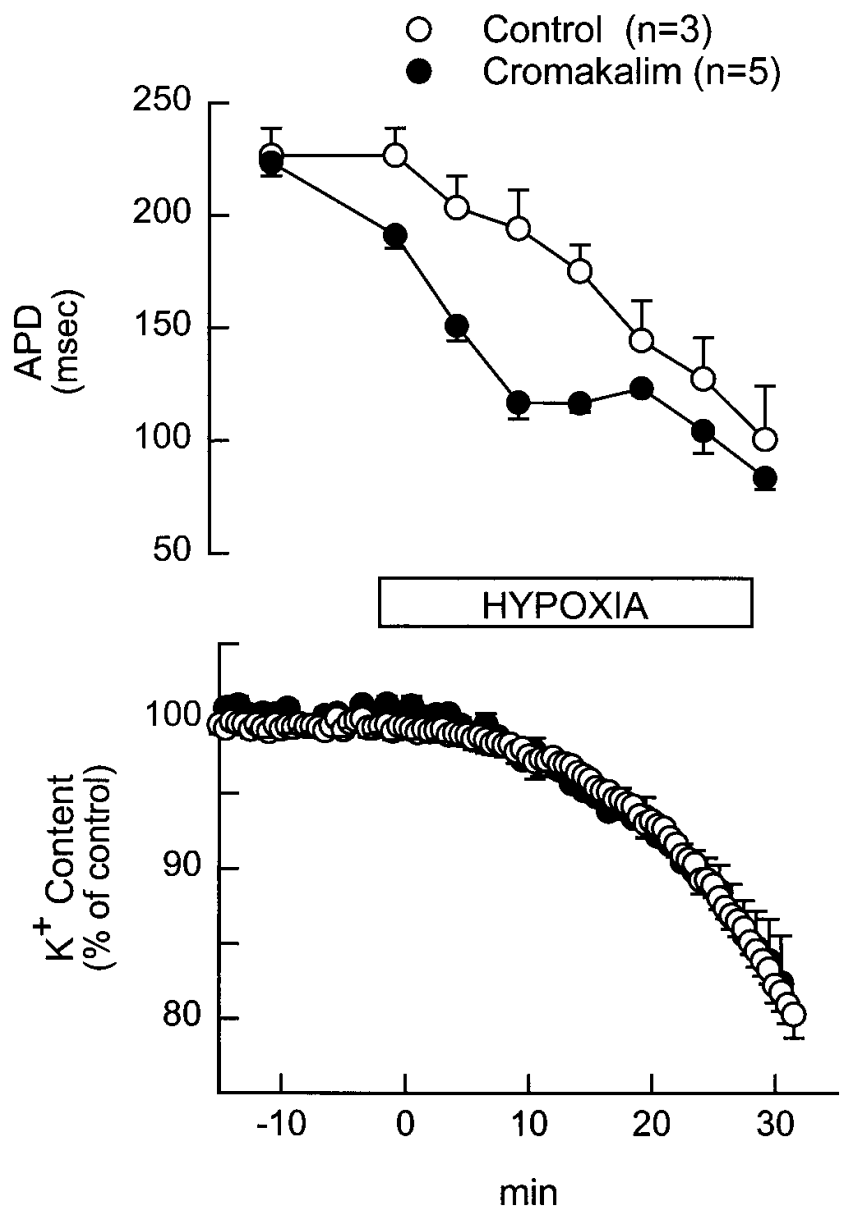

Figure 4. Effects of substrate-free hypoxia $\pm 5 \mu \mathrm{M}$ cromakalim on action potential duration at $90 \%$ repolarization $(A P D)$ and tissue ${ }^{42} \mathrm{~K}$ content in isolated rabbit ventricular septa. Although APD shortening during hypoxia was enhanced by cromakalim (top), the rate at which tissue $\mathrm{K}$ content decreased was unchanged (bottom). Values are mean $\pm 1 \mathrm{SEM}$. Temperature $37^{\circ} \mathrm{C}$, heart rate $75 \mathrm{bpm}$.

In contrast, inhibiting the activation of $\mathrm{K}_{\mathrm{ATP}}$ channels during hypoxia by pretreating septa with a high concentration of glibenclamide $(100 \mu \mathrm{M})$, a $\mathrm{K}_{\mathrm{ATP}}$ channel antagonist, significantly inhibited the decrease in tissue $\mathrm{K}$ content during $30 \mathrm{~min}$ of substrate-free hypoxia by $55 \%$ (from $31 \pm 9 \%, n=5$, decrease in the absence of glibenclamide to $14 \pm 4 \%, n=3$, decrease in its presence) (Fig. 5). In a separate group of four septa, $100 \mu \mathrm{M}$ glibenclamide did largely prevent the increase in unidirectional K efflux during hypoxia (Fig. 5). However, glibenclamide did not significantly decrease the rate of APD shortening during hypoxia ( $n=7$ including both the ${ }^{42} \mathrm{~K}$ efflux and uptake experiments), as would have been expected if its only effect were to selectively block $\mathrm{K}_{\mathrm{ATP}}$ channels. These findings raise the possibility that nonspecific effects of such high concentrations of glibenclamide may have contributed to its inhibition of tissue $\mathrm{K}$ loss during hypoxia.

\section{Discussion}

Mechanism of net K loss during hypoxia. Despite its key importance as an arrhythmogenic factor, the cause of net cellular $\mathrm{K}$ loss during myocardial ischemia and hypoxia has remained elusive. This study contributes several important observations towards an understanding of the underlying mechanism: (a) activation of $\mathrm{K}_{\mathrm{ATP}}$ channels, or, by analogy, other time-independent $\mathrm{K}$ channels, is not the primary cause of net cellular $\mathrm{K}$ loss during hypoxia or ischemia. At most, activation of these channels has a modest modulatory effect; $(b)$ the primary factor responsible for net $\mathrm{K}$ loss is altered $\mathrm{Na}$ fluxes, which cause intracellular $\mathrm{Na}$ to accumulate and, in doing so, displace intracellular K. We infer this conclusion from the near elimination of net $\mathrm{K}$ loss during hypoxia when $\mathrm{Na}$ influx pathways were inhibited. Although we did not measure intracellular $\mathrm{Na}$ accumulation directly in this study, numerous studies have consistently documented that intracellular $\mathrm{Na}$ rises during hypoxia at a rate equal to or in excess of $\mathrm{K}$ loss (for review, see reference 1). In the one study in which intracellular $\mathrm{Na}$ gain and $\mathrm{K}$ loss were measured simultaneously during hypoxia (5), the increase in intracellular Na mirrored the decrease in intracellular $\mathrm{K}$ nearly exactly, even replicating the same triphasic pattern, so that the sum of intracellular $[\mathrm{K}]+[\mathrm{Na}]$ remained virtually constant throughout. Although we did not study ischemia here, most studies in ischemic heart have also shown that intracellular $\mathrm{Na}$ rises significantly, at a rate of $0.5-1.0 \mathrm{mM} / \mathrm{min}$ (for review, see reference 1). If the accumulating $\mathrm{Na}$ replaced intracellular $\mathrm{K}$ on a mole-to-mole basis, the rate of intracellular $\mathrm{K}$ loss would readily account for the observed rate of extracellular $\mathrm{K}$ accumulation $(0.5-1.0 \mathrm{mM} / \mathrm{min})$ during acute ischemia, especially considering that the extracellular water space into which the $\mathrm{K}$ effluxes is smaller than the intracellular water space by a factor of $\sim 2$ (i.e., a $0.5 \mathrm{mM} / \mathrm{min}$ loss of intracellular [K] would be amplified to a $1 \mathrm{mM} / \mathrm{min}$ increase in extracellular $[\mathrm{K}])$. During ischemia, the extracellular space becomes progressively dehydrated, increasing this amplification further, and also directly contributing, to a modest extent, to extracellular $[\mathrm{K}]$ accumulation independent of net $\mathrm{K}$ loss (12).

We envision that intracellular $\mathrm{Na}$ accumulation leads to net $\mathrm{K}$ loss because of the need to maintain both electroneutrality of charge movement and osmotic balance during hypoxia or ischemia. Na ions accumulating in the cytosol will markedly alter membrane potential unless their positive charge is balanced by an equal and opposite charge movement, either by the loss of another cation or gain of an anion. For example, if the positive charge associated with a $1 \mathrm{mM}$ increase in intracellular [Na] was uncompensated, the myocyte would be depolarized by $20 \mathrm{~V}$ (assuming a typical myocyte contains $20 \mathrm{pl}$ of nonmitochondrial water and has a membrane capacitance of $140 \mathrm{pF}$ ). Among cations, $\mathrm{K}$ is the most likely to serve this charge-balancing role, since it is the most ubiquitous intracellular cation and has a high membrane permeability. The most important pathway for this $\mathrm{K}$ efflux is likely to involve various $\mathrm{K}$ channels, including inward rectifier $\mathrm{K}$ channels during diastole and voltage-gated $\mathrm{K}$ channels during systole, as well as $\mathrm{K}_{\mathrm{ATP}}$ channels (during both systole and diastole). Alternatively, balancing charge by the gain of anions would increase intracellular osmolarity, activating osmoregulatory mechanisms to reestablish osmotic balance such that the sum of intracellular cations (i.e., predominantly $[\mathrm{K}]+[\mathrm{Na}]$ ), like the sum of anion concentrations, remains $\sim 150 \mathrm{mM}$. As the major cardiac osmoregulatory mechanism (13), Na-K-2Cl cotransport when so activated would promote net $\mathrm{K}$ loss. This is consistent with the finding that furosemide, an inhibitor of $\mathrm{Na}-\mathrm{K}-2 \mathrm{Cl}$ cotransport, reduced the rate of extracellular $[\mathrm{K}]$ accumulation during acute ischemia by about one-third (14). 

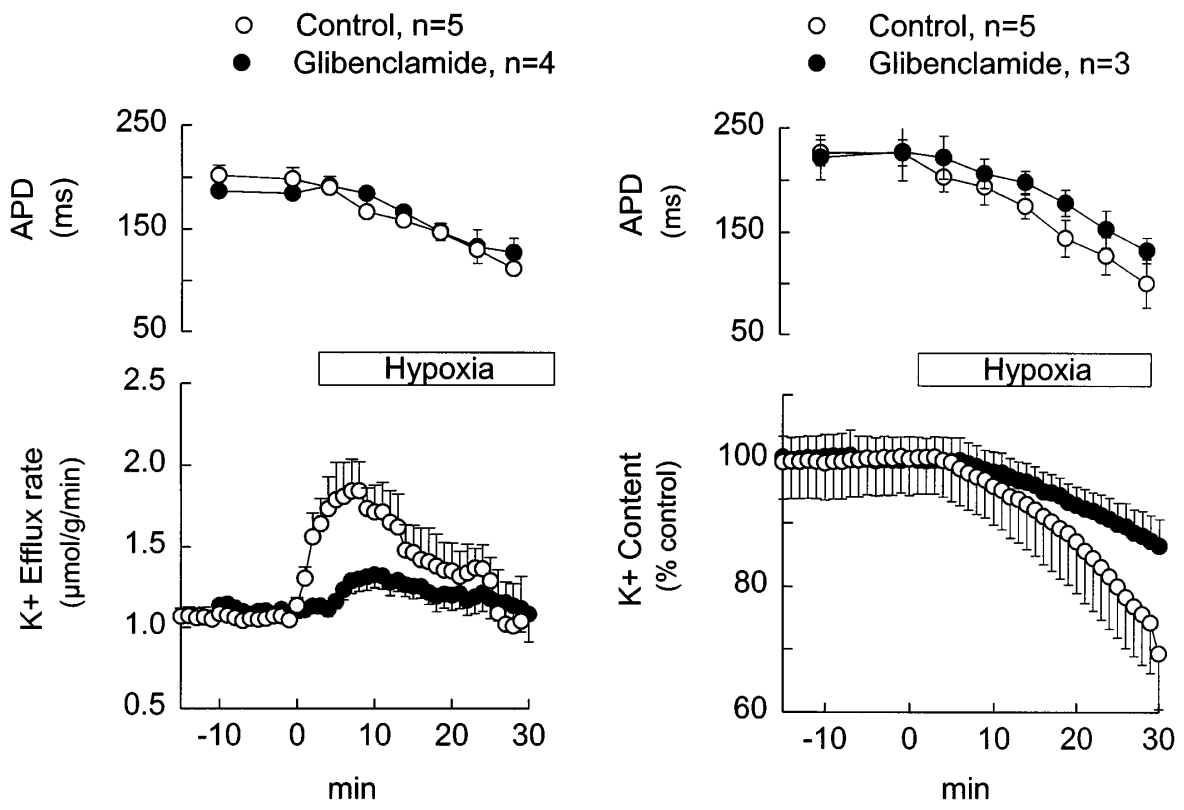

Figure 5. Effects of substrate-free hypoxia $\pm 100 \mu \mathrm{M}$ glibenclamide on action potential duration at $90 \%$ repolarization $(A P D)$, unidirectional $\mathrm{K}$ efflux rate, and tissue ${ }^{42} \mathrm{~K}$ content in isolated rabbit ventricular septa. (Left panels) Although the rate of APD shortening during $30 \mathrm{~min}$ of substrate-free hypoxia (beginning at time zero) was not significantly affected by pretreatment with glibenclamide for $10 \mathrm{~min}$ (top), the increase in unidirectional $\mathrm{K}$ efflux rate was markedly reduced (bottom). (Right panels) The decrease in tissue $\mathrm{K}$ content during $30 \mathrm{~min}$ of substrate-free hypoxia was also significantly reduced by preexposure to $100 \mu \mathrm{M}$ glibenclamide (bottom), despite no change in the rate of APD shortening. Values are mean \pm 1 SEM. Temperature $37^{\circ} \mathrm{C}$, heart rate $75 \mathrm{bpm}$.

If cellular $\mathrm{K}$ loss during hypoxia and ischemia is a passive reflection of intracellular $\mathrm{Na}$ accumulation, then to understand the mechanism of $\mathrm{K}$ loss one must obviously understand the mechanism of intracellular $\mathrm{Na}$ gain. Unidirectional $\mathrm{Na}$ efflux has been measured using ${ }^{24} \mathrm{Na}$ in the normoxic ventricle beating at 80 beats per minute, and averaged $4 \mu \mathrm{mol} / \mathrm{min}$ per gram wet weight, falling to $0.25 \mu \mathrm{mol} / \mathrm{min}$ per gram when pacing was stopped and the heart was quiescent (11). These values can be converted to 8.0 and $0.5 \mathrm{mM} / \mathrm{min}$, respectively, assuming a value of $0.5 \mathrm{ml}$ of nonmitochondrial water per gram wet weight $(15,16)$. In the steady-state, unidirectional $\mathrm{Na}$ efflux and influx are balanced. $\mathrm{Na}$ efflux is mediated by the Na-K pump, and $\mathrm{Na}$ influx by the following pathways: the $\mathrm{Na}$ current; $\mathrm{Na}-\mathrm{Ca}$ exchange, which exchanges three $\mathrm{Na}$ ions for each $\mathrm{Ca}$ ion entering the cytosol via the Ca current (17); $\mathrm{Na}-\mathrm{H}$ exchange; $\mathrm{Na}-\mathrm{K}$ 2Cl cotransport (13); Na-Cl cotransport (13); a background (leak) Na current; and nonselective cation currents. Fig. 6 summarizes the quantitative relationships between the $\mathrm{Na}$ influx pathways in the normoxic beating heart. For intracellular $\mathrm{Na}$ to accumulate at $0.5 \mathrm{mM} / \mathrm{min}$, it is apparent that only a small imbalance $(\sim 10 \%)$ between unidirectional $\mathrm{Na}$ influx and efflux is needed. Any imbalance implies that the Na pump is unable to compensate for the degree of $\mathrm{Na}$ influx, whether normal, decreased or increased. Whether the primary defect is due to inhibition of the Na-K pump or an increase in Na influx beyond the capacity of the pump to compensate, is uncertain. Although the bulk cytosolic ATP level does not fall rapidly enough to expect significant inhibition of the Na-K pump during early hypoxia (6), it is possible that ATP levels in the immediate vicinity of the pump may be depleted more rapidly. Several observations also suggest that $\mathrm{Na}$ influx might increase during early hypoxia. $\mathrm{Na}$ influx via $\mathrm{Na}-\mathrm{H}$ exchange, although a minor component of $\mathrm{Na}$ influx under normoxic conditions (Fig. 6), accelerates markedly during hypoxia in response to intracellular proton generation. Modification of $\mathrm{Na}$ channel properties promoting $\mathrm{Na}$ influx at hyperpolarized membrane potentials has been reported during hypoxia (18) and in response to the ischemic metabolite lysophosphatidylcholine (19). Recently, activation of a nonselective current by meta- bolic inhibition has also been reported (20). It is also notable from Fig. 6 that the major $\mathrm{Na}$ influx pathway under normal conditions arises from $\mathrm{Na}-\mathrm{Ca}$ exchange expelling $\mathrm{Ca}$ entering via the L-type $\mathrm{Ca}$ channel. This is consistent with the observations that reducing the L-type Ca current by verapamil or lowered $[\mathrm{Ca}]_{0}$ markedly decreased the rate of extracellular $[\mathrm{K}]$ accumulation during ischemia $(21,22)$.

Our data also indirectly support an increase in inward currents potentially contributing to Na loading during hypoxia. With cromakalim, a $48 \%$ increase in unidirectional $\mathrm{K}$ efflux rate was sufficient to shorten APD by $69 \%$, whereas during hypoxia an even larger $75 \%$ increase in unidirectional $\mathrm{K}$ efflux rate during hypoxia caused a much smaller (36\%) decrease in APD. The preservation of APD in the face of an equivalent increase in membrane K permeability can only be explained by a concomitant activation of an inward current, such as an $\mathrm{Na}$ or nonselective cation current. However, the greater degree of APD shortening for the same apparent increase in unidirectional K efflux during cromakalim versus hypoxia could be artifactual. With the ${ }^{42} \mathrm{~K}$ washout technique, ${ }^{42} \mathrm{~K}$ backflux from the interstitial to intracellular compartment may underestimate the true unidirectional $\mathrm{K}$ efflux rate. If the $\mathrm{Na}-\mathrm{K}$ pump was significantly inhibited during hypoxia, the increase in unidirectional $\mathrm{K}$ efflux would then be underestimated to a lesser extent during hypoxia than during cromakalim exposure. The ${ }^{42} \mathrm{~K}$ backflux problem affects only unidirectional $\mathrm{K}$ flux calculations, and has no effect on measurement of tissue $\mathrm{K}$ content with ${ }^{42} \mathrm{~K}$.

Does activation of $K_{A T P}$ channels modulate net $K$ loss during hypoxia and ischemia? The finding that selective activation of $\mathrm{K}_{\mathrm{ATP}}$ channels does not directly cause net $\mathrm{K}$ loss does not rule out the possibility that their activation may modulate net $\mathrm{K}$ loss during hypoxia and ischemia by affecting intracellular $\mathrm{Na}$ accumulation. By accelerating APD shortening and shifting the average membrane potential to more negative (hyperpolarized) values, activation of $\mathrm{K}_{\mathrm{ATP}}$ channels during hypoxia and ischemia could facilitate intracellular $\mathrm{Na}$ accumulation by decreasing $\mathrm{Na}$ efflux by the electrogenic $\mathrm{Na}-\mathrm{K}$ pump (which is inhibited by hyperpolarization) and potentiating $\mathrm{Na}$ 


\section{Myocardial Na Balance}

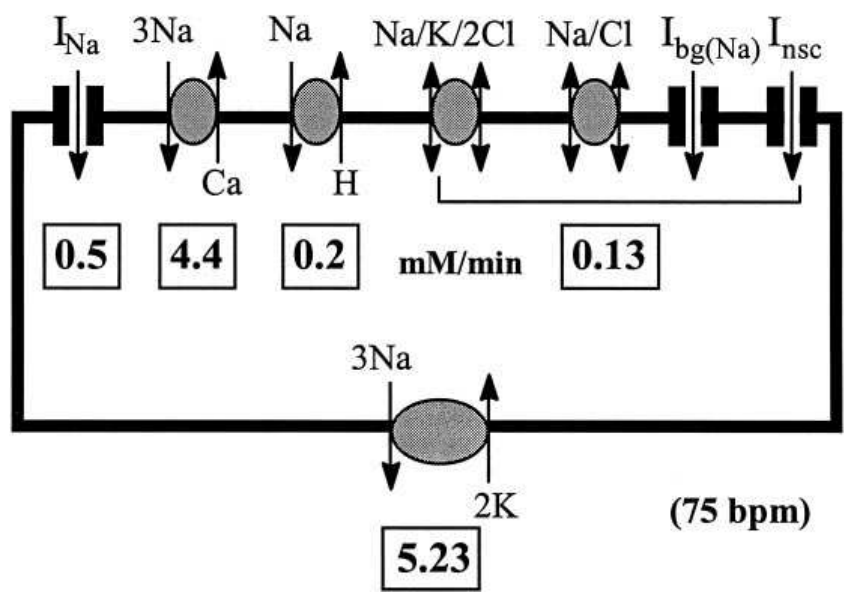

Figure 6. Estimated unidirectional $\mathrm{Na}$ fluxes in the beating ventricle. Estimates are based on the assumptions that a typical rabbit ventricular myocyte had a volume of $20 \mathrm{pl}$ nonmitochondrial water, capacitance of $140 \mathrm{pF}$ (33), and was paced at $75 \mathrm{bpm}$. Na influx via the $\mathrm{Na}$ current was integrated from the Luo-Rudy ventricular action potential model (34), and agreed well with calculated charge $(\sim 15 \mathrm{pC})$ needed to depolarize a myocyte from -80 to $+20 \mathrm{mV}$ at 75 times each minute. $\mathrm{Na}$ influx via $\mathrm{Na}-\mathrm{Ca}$ exchange was calculated assuming that with each beat, three $\mathrm{Na}$ ions are exchanged for each $\mathrm{Ca}$ ion entering the myocyte via the L-type Ca current, averaging $68 \mathrm{pC}$ of $\mathrm{Ca}$ per beat as integrated from the Luo-Rudy action potential model with a 0.17 -s action potential duration (35). This value agreed reasonably well with the estimate in rabbit ventricle that $20 \%$ of the 50 $\mu \mathrm{mol} / \mathrm{kg}$ of Ca-activating contraction per beat is removed from the cytosol by $\mathrm{Na}-\mathrm{Ca}$ exchange (36). The remaining $\mathrm{Na}$ influx is assumed to total $6 \%$ of the excitation-dependent $\mathrm{Na}$ influx (i.e., $\mathrm{Na}$ influx via the $\mathrm{Na}$ current and $\mathrm{Na}-\mathrm{Ca}$ exchange), based on the Na flux measurements by Langer (11). From Lazdunski (37), $60 \%$ of this $6 \%$ can be attributed to $\mathrm{Na}-\mathrm{H}$ exchange, and the remaining $40 \%$ to miscellaneous $\mathrm{Na}$ influx pathways, including $\mathrm{Na}-\mathrm{K}-2 \mathrm{Cl}$ cotransport, $\mathrm{Na}-\mathrm{Cl}$ cotransport, background $\mathrm{Na}$ channels and nonselective cation channels. The total estimated unidirectional $\mathrm{Na}$ influx of $5.2 \mathrm{mM} / \mathrm{min}$ agrees reasonably well with the measured unidirectional $\mathrm{Na}$ efflux of $4 \mu \mathrm{mol} / \mathrm{min}$ per gram wet weight, or $8.0 \mathrm{mM} / \mathrm{min}$, assuming $1 \mathrm{gram}$ wet weight $=0.5$ liters of intracellular water $(15,16)$, in canine ventricle beating at $80 \mathrm{bpm}(11)$.

influx through $\mathrm{Na}-\mathrm{Ca}$ exchange, $\mathrm{Na}$ currents and nonselective cation currents (by increasing the driving force for $\mathrm{Na}$ entry). The results with glibenclamide, which reduced net $\mathrm{K}$ loss by $55 \%$ during hypoxia in this preparation and by an average of $\sim 20 \%$ during ischemia in various preparations (reviewed in reference 1), are consistent with this hypothesis. In contrast, the results with cromakalim do not support this hypothesis, since cromakalim did not potentiate net $\mathrm{K}$ loss during either hypoxia (Fig. 4) or ischemia in rabbit septa (23), despite significantly accelerating the rate of APD shortening in both settings. The reason for this discrepancy is unclear. We have more confidence in the results with cromakalim, since only very high concentrations of glibenclamide, one to two orders of magnitude higher than the usual concentrations needed to block $\mathrm{K}_{\mathrm{ATP}}$ channels in membrane patches, were effective at reducing net $\mathrm{K}$ loss during hypoxia or ischemia in rabbit septa (24). These high concentrations were also ineffective at pre- venting APD shortening during hypoxia, raising the possibility that nonspecific effects were present. Glibenclamide has previously been demonstrated to block $\mathrm{Cl}$ and other $\mathrm{K}$ channels, modulate $\mathrm{Ca}$ release, alter lactate metabolism during normoxia and hypoxia, and affect fatty acid metabolism (24-30). Since the reduction of net $\mathrm{K}$ loss by $\mathrm{K}_{\mathrm{ATP}}$ channel antagonists is the only real evidence suggesting a role for these channels in promoting ischemic and $\mathrm{K}$ loss, this is an important issue to resolve.

Limitations. Several limitations of this study should be acknowledged. As mentioned earlier, we did not have the means to directly measure intracellular $[\mathrm{Na}]$ in this preparation to determine whether the rates of intracellular $\mathrm{Na}$ accumulation and $\mathrm{K}$ loss were quantitatively comparable, although data from the literature strongly support this contention (5). In interpreting our findings, we have made the assumption that the mechanisms of net $\mathrm{K}$ loss during hypoxia and ischemia are similar. Although they have many features in common, we cannot exclude the possibility that the underlying mechanisms may be different. In the septal preparation, for example, the net $\mathrm{K}$ loss was markedly decreased in the unpaced, quiescent heart during both hypoxia and ischemia (31), but in other species, quiescence had little effect on the rate of ischemic extracellular K accumulation (1). We interpreted the decreased net $\mathrm{K}$ loss during hypoxia in the unpaced, quiescent heart as due to the reduction in $\mathrm{Na}$ influx, but it is also possible that the effect was indirectly caused by reduced cardiac work resulting in a lesser metabolic supply-demand imbalance. However, in quiescent hearts treated with tetrodotoxin, verapamil, EIPA, and furosemide to block Na influx more completely, net K loss was further reduced despite no obvious additional reduction in energy demand.

Physiological implications. The hypothesis that net $\mathrm{K}$ loss during hypoxia and ischemia is primarily driven by intracellular $\mathrm{Na}$ accumulation has important implications. Intracellular $\mathrm{Na}$ accumulation in these settings is also a major factor promoting intracellular $\mathrm{Ca}$ overload via $\mathrm{Na}-\mathrm{Ca}$ exchange during reoxygenation or reperfusion (32). By also linking intracellular $\mathrm{Na}$ accumulation to net $\mathrm{K}$ loss, our findings therefore suggest that this factor plays a central role in the pathogenesis of the two most dire consequences of acute ischemia: ventricular arrhythmias and reperfusion injury. It is a key challenge to understand how cardiac $\mathrm{Na}$ fluxes become unbalanced so rapidly during acute myocardial ischemia and hypoxia, and, in particular, whether the primary defect is $\mathrm{Na}-\mathrm{K}$ pump inhibition, or increased $\mathrm{Na}$ influx.

\section{Acknowledgments}

The authors thank Tan Duong and Laura Alexander for technical assistance.

This study was funded by National Institutes of Health SCOR in Sudden Cardiac Death P50 HL-52319, RO1 HL-36729, the Laubisch Cardiovascular Research Fund, and the Kawata Endowment.

\section{References}

1. Wilde, A., and G. Aksnes. 1995. Myocardial potassium loss and cell depolarization in ischemia and hypoxia. Cardiovasc. Res. 29:1-15.

2. Janse, M.J., and A.L. Wit. 1989. Electrophysiological mechanisms of ventricular arrhythmias resulting from myocardial ischaemia and infarction. Physiol. Rev. 69:1049-1168.

3. Rau, E.E., K.I. Shine, and G.A. Langer. 1977. Potassium exchange and mechanical performance in anoxic mammalian myocardium. Am. J. Physiol. 
232:H84-H94.

4. Shine, K.I., A.M. Douglas, and N. Ricchiuti. 1977. ${ }^{42}$ K exchange during myocardial ischemia. Am. J. Physiol. 232:H564-H570.

5. Fiolet, J.W.T., A. Baartscheer, C.A. Schumacher, R. Coronel, and H.F. ter Welle. 1984. The change of the free energy of ATP hydrolysis during global ischemia and anoxia in the rat heart. J. Mol. Cell. Cardiol. 16:1023-1036.

6. Weiss, J.N., N. Venkatesh, and S.T. Lamp. 1992. ATP-sensitive K channels and cellular $\mathrm{K}$ loss in hypoxic and ischaemic mammalian ventricle. J. Physiol. 447:649-673.

7. Nichols, C.G., C. Ripoll, and W.J. Lederer. 1991. ATP-sensitive potassium channel modulation of the guinea pig ventricular action potential and contraction. Circ. Res. 68:280-287.

8. Ferrero, J.M., Jr., J. Saiz, J.M. Ferrero, and N.V. Thakor. 1996. Simulation of action potentials from metabolically impaired cardiac myocytes. Role of ATP-sensitive K current. Circ. Res. 79:208-221.

9. Weiss, J.N., S.T. Lamp, and K.I. Shine. 1989. Cellular K loss and anion efflux during myocardial ischaemia and metabolic inhibition. Am. J. Physiol. 256: H1165-H1175.

10. Weiss, J.N., and R.C. Shieh. 1994. Potassium loss during myocardial ischaemia and hypoxia: Does lactate efflux play a role? Cardiovasc. Res. 28:11251132.

11. Langer, G.A. 1974. Ionic movements and the control of contraction. In The Mammalian Myocardium. G.A. Langer and A.J. Brady, editors. John Wiley \& Sons, New York. 198-201.

12. Yan, G.X., J. Chen, K.A. Yamada, A.G. Kleber, and P.B. Corr. 1996. Contribution of extracellular $\mathrm{K}$ accumulation in myocardial ischaemia of the rabbit. J. Physiol. 490:215-228.

13. Drewnowska, K., and C.M. Baumgarten. 1991. Regulation of cellular volume in rabbit ventricular myocytes: bumetanide, chlorthiazide and ouabain. Am. J. Physiol. 260:C122-C131.

14. Mitani, A., and M.J. Shattock. 1992. Role of Na-Activated K channel, $\mathrm{Na}-\mathrm{K}-\mathrm{Cl}$ cotransport, and Na-K pump in $[\mathrm{K}]_{\mathrm{e}}$ changes during ischemia in rat heart. Am. J. Physiol. 263:H333-H340.

15. Sipido, K.R., and W.G. Wier. 1991. Flux of Ca across the sarcoplasmic reticulum of guinea-pig cardiac cells during excitation-contraction coupling. $J$. Physiol. 435:605-630.

16. Fabiato, A. 1983. Calcium induced release of calcium from cardiac sarcoplasmic reticulum. Am. J. Physiol. 245:C1-C14.

17. Bridge, J.H., J.R. Smolley, and K.W. Spitzer. 1990. The relationship between charge movements associated with $\mathrm{I}_{\mathrm{Ca}}$ and $\mathrm{I}_{\mathrm{Na}-\mathrm{Ca}}$ in cardiac myocytes. Science (Wash. DC). 248:376-378.

18. Jue, Y., D.A. Saint, and P.W. Gage. 1996. Hypoxia increases persistent sodium current in rat ventricular myocytes. J. Physiol. 497:337-347.

19. Undrovinas, A.I., I.A. Fleidervish, and J.C. Makielski. 1992. Inward sodium current at resting potentials in single cardiac myocytes induced by the ischemic metabolite lysophosphatidylcholine. Circ. Res. 71:1231-1241.

20. Goldhaber, J.I., T.K. Duong, and J.N. Weiss. 1996. Activation of a nonselective cation current may drive net cellular $\mathrm{K}$ loss during metabolic inhibition. Biophys. J. 70:261a (Abstr.)

21. Weiss, J., and K.I. Shine. 1982. Extracellular K accumulation during myo- cardial ischemia in isolated rabbit heart. Am. J. Physiol. 242:H619-H628.

22. Watanabe, I., T.A. Johnson, C.L. Engle, C. Graebner, M.G. Jenkins, and L.S. Gettes. 1989. Effects of verapamil and propranolol on changes in extracellular $\mathrm{K}, \mathrm{pH}$, and local activation during graded coronary flow in the pig. Circulation. 79:939-947.

23. Venkatesh, N., J.S. Stuart, S.T. Lamp, L.D. Alexander, and J.N. Weiss. 1992. Activation of ATP-sensitive K channels by cromakalim-effects of cellular $\mathrm{K}$ loss and cardiac function in ischemic and reperfused mammalian ventricle. Circ. Res. 71:1324-1333.

24. Venkatesh, N., S.T. Lamp, and J.N. Weiss. 1991. Sulfonylureas, ATPsensitive $\mathrm{K}$ channels and cellular $\mathrm{K}$ loss during hypoxia, ischaemia and metabolic inhibition in mammalian ventricle. Circ. Res. 69:623-637.

25. Wilde, A.A.M., D. Escande, C.A. Schumacher, D. Thuringer, M. Mestre, J.W.T. Fiolet, and M.J. Janse. 1990. Potassium accumulation in the globally ischaemic mammalian heart: a role for the ATP-sensitive K channel. Circ. Res. 67:835-843.

26. Tominaga, M., M. Horie, S. Sasayama, and Y. Okada. 1995. Glibenclamide, an ATP-sensitive K channel blocker, inhibits cardiac cAMP-activated $\mathrm{Cl}$ conductance. Circ. Res. 77:417-423.

27. Reeve, H.L., P.F.T. Vaughan, and C. Peers. 1992. Glibenclamide inhibits a voltage-gated $\mathrm{K}$ current in the human neuroblastoma cell line SH-SY5Y. Neurosci. Lett. 135:37-40.

28. Chopra, L.C., C.H.C. Twort, and J.P.T. Ward. 1992. Direct action of BRL 38227 and glibenclamide on intracellular calcium stores in cultured airway smooth muscle of rabbit. Br. J. Pharmacol. 105:259-260.

29. Bian, K., and K. Hermsmeyer. 1992. Enhancement of rat aorta Ca channel current by glyburide. FASEB J. 6:259-260a (Abstr.)

30. Cook, G.A. 1987. The hypoglycemic sulphonylureas glyburide and tolbutamide inhibit fatty acid oxidation by inhibiting carnitine palmitoyl-transferase. J. Biol. Chem. 262:4968-4972.

31. Weiss, J.N., and K.I. Shine. 1986. Effects of heart rate on extracellular $\left[\mathrm{K}^{+}\right]$accumulation during myocardial ischemia. Am. J. Physiol. H982-H991.

32. Silverman, H.S., and M.D. Stern. 1994. Ionic basis of ischaemic cardiac injury: insights from cellular studies. Cardiovasc. Res. 28:581-597.

33. Satoh, H., L.M.D. Delbridge, L.A. Blatter, and D.M. Bers. 1996. Surface:volume relationship in cardiac myocytes studied with confocal microscopy and membrane capacitance measurements: species-dependence and developmental effects. Biophys. J. 70:1494-1504.

34. Luo, C.H., and Y. Rudy. 1991. A model of the ventricular cardiac action potential. Depolarization, repolarization and their interaction. Circ. Res. 68: 1501-1526.

35. Luo, C.H., and Y. Rudy. 1994. A dynamic model of the cardiac ventricular action potential. 1. Simulations of ionic currents and concentration changes. Circ. Res. 74:1071-1096.

36. Bers, D.M. 1991. Excitation-Contraction Coupling and Cardiac Contractile Force. Kluwer Academic Publishers, Boston. p. 91.

37. Lazdunski, M., C. Frelin, and P. Vigne. 1985. The sodium/hydrogen exchange system in cardiac cells: Its biochemical and pharmacological properties and its role in regulating internal concentrations of sodium and internal $\mathrm{pH} . J$. Mol. Cell. Cardiol. 17:1029-1042. 